\section{A SURVEY OF GASTRO-INTESTINAL PARASITIC INFECTION IN NILGIRI LANGUR (SEMNOPITHECUS JOHNII) AT KALAKKAD-MUNDANTHURAI TIGER RESERVE, TAMIL NADU}

\author{
S. Rajendran*, P.C. Saseendran, H. Subramanian, \\ R. Chitra and N. Yuvaraj \\ College of Veterinary and Animal Sciences, Mannuthy, Kerala, India \\ * Corresponding author: 13/9, Thiru, Vi. Ka. Street, Veerappan \\ Chatram, Erode, Tamil Nadu 638004, India. \\ Email: cvsrajesh@yahoo.co.in
}

The Nilgiri Langur (Semnopithecus johnii) is an endangered Primate found exclusively in the Western Ghats (Kurup, 1975), being distributed from the Kanyakumari hills $\left(8^{\circ} \mathrm{N}\right)$ at the southern tip of the Indian peninsula to the Coorg hills in Karnataka $\left(12^{\circ} \mathrm{N}\right)$. It is usually found in tropical evergreen forests at altitudes above $500 \mathrm{~m}$. However, in Tirunelveli, Tamil Nadu, Nilgiri Langur is found even in foot hills where the riverine forests are contiguous with the forests of upper slopes. They are folivorous, young leaves being the dominant food item. Leaves, seeds, fruits, flowers and flower buds are consumed from over 90 plant species. Nilgiri Langur has presently suffered population decline mainly due to habitat destruction, poaching for the supposedly medicinal properties of its meat, habitat loss due to natural calamities and diseases. Recent survey in Tamil Nadu have indicated further decline from the earlier estimates (Sunderaj \& Johnsingh, 2001). Data on the diseases and mortality of the wild stock are still meager. This paper attempts to assess the parasitic load of the Nilgiri Langur.

Sixteen fresh faecal samples were collected from different points of Kalakkad-Mundanthurai Tiger Reserve (KMTR) $\left(895 \mathrm{~km}^{2}\right.$ in area; $\left.8^{0} 25^{\prime}-8^{0} 53^{\prime} \mathrm{N} \& 77^{0} 10^{\prime}-77^{0} 35^{\prime} \mathrm{E}\right)$. The samples were preserved in $10 \%$ formalin and brought to the laboratory for direct examination. On concentration and centrifugation in saturated salt solution as per Georgi's (1985) technique, the samples were examined for parasitic infection.

Analysis of the samples revealed that parasitism was highly prevalent among them (Table 1) and the samples were infected with nematode infection. The examined samples showed infection of 100\% Strongyles, 25\% Trichuris, $18.74 \%$ Strongyloides and $18.75 \%$ Spirurids. Seven samples (43.75\%) were found to be infected with Strongyles only and nine samples were positive for mixed infection $(56.25 \%)$. Among mixed infection, two samples $(12.5 \%)$ were combination of Strongyles and Strongyloides, four samples (25\%) a combination of Strongyles and Trichuris and one sample (6.25\%) was combination of Strongyles, Strongyloides and Spirurids.

Adkoli et al. (1986) reported strongyloides in zoo animals while Joseph et al. (1999) and Xavier et al. (2000) reported Trichuris in the faecal samples of Nilgiri Langur in Silent Valley National Park. The presence of these parasites may be related to the feeding habit of Nilgiri Langur. The infected animals can contaminate all feeding material in the process of their defecation from tree tops (Xavier et al., 2000). The ingestion of food with contaminated parasitic eggs and their third stage larvae can cause infection (Soulsby, 1982). Since, Nilgiri Langur feeds on a variety of plant materials, periodic evacuation of parasites from the digestive tract will be a common feature. Only in old animals and siblings a heavy parasitic infection may become fatal (Joseph et al., 1999). Further extensive survey in different ranges of KMTR is essential to understand the implication of parasitism in Nilgiri Langur.

\section{REFERENCES}

Adkoli, N.S., C.K. Mondal and J.N. Ghose (1986). Parasitic infection in zoo animals. Zoo Zen 2(3): 22-26.

Georgi, J.R. (1985). Parasitology for Veterinarians. $4^{\text {th }}$ edition. W.B. Saunders, London, 344pp.

Joseph, G.K., K.M. Pallai, F. Xavier, Bindu Michael and M. Amrithraj (1999). A coprological survey of parasites in two endangered primates of Silent Valley National Park, Kerala. Indian Forester 125(10): 1027-1030.

Kurup, G.U. (1975). Status of Nilgiri Langur, Presbytis johnii in the Anamalai Cardamom and Nilgiri Hills of the Western Ghats. Journal of Bombay Natural History Society 65: 283-292.

Soulsby, E.J.L. (1982). Helminths, Arthropodes and Protozoa of Domestic animals, pp. 808-815. Lea and Febiger, Philadelphia.

Sunderraj, S.F.W. and A.J.T. Johnsingh (2001). Impact of biotic disturbances on Nilgiri Langur habitat, demography and group dynamics. Current Science 80(3): 428-436.

Xavier, F., G.K., Joseph, Bindu Michael and K. Bijula (2000). A coprological survey of parasites of seven mammal groups at Silent Valley National Park, Kerala. Zoos' Print Journal 15(6): 279-280.

Table 1. Incidence of parasitic infection and mixed infection among Nilgiri Langur at KMTR

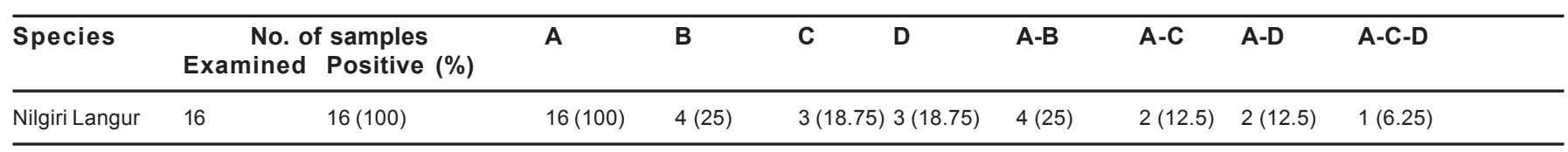

A - Strongyle; B - Trichuris; C - Strongyloides; D - Spirurids; Values in parenthesis denotes percentage of incidence. 